\title{
Is a word to the wise indeed enough? ECB statements and the predictability of interest rate decisions
}

\author{
David-Jan Jansen* \\ De Nederlandsche Bank
}

\author{
Jakob de Haan \\ University of Groningen \\ CESifo
}

\section{February 7, 2006}

\begin{abstract}
We show that comments by euro area central bankers contain information on future ECB interest rate decisions, but that the comments mainly reflect recent developments in macroeconomic variables. Furthermore, models using only communication variables are outperformed by straightforward Taylor rule models. During the first years of the European Economic and Monetary Union, comments by ECB Executive Board members and high-level Bundesbank policy-makers were more informative than comments by national central bank presidents. We also find that differences of opinion were informative when they concerned the outlook for economic growth. Finally, our results suggest that the ECB used communication especially to signal interest rate increases.
\end{abstract}

JEL classifications: E43, E52, E58

Keywords: central bank communication, interest rate decisions, ECB, Taylor rule, ordered probit models

${ }^{*}$ Corresponding author. De Nederlandsche Bank, Research Division, P.O. Box 98, 1000 AB Amsterdam, The Netherlands, tel.: +31-20-5243170, fax: +31-20-5242529, e-mail: d.jansen@dnb.nl. 


\section{Introduction}

Communication has become a key policy instrument for central bankers. The main benefit of communication is the opportunity to directly influence private sector expectations. There is increasing evidence that central bank communication affects developments in financial markets (see, for example, Kohn and Sack (2003), Bernanke, Reinhart and Sack (2004) or Gürkaynak, Sack and Swanson (2005)). In turn, financial market participants pay close attention to what central bankers say as these comments are an important and direct source of information on future policy decisions.

In all, it seems that the words of central banks may well be as important as their actions. Naturally, this invites questions on the precise nature of the relationship between communication and subsequent interest rate decisions. Does communication yield information on future decisions that could not be obtained through other sources? Or, is communication as informative as macroeconomic developments? To what extent is communication a reflection of these developments? The first aim of this paper is to study these issues. We do this by analysing statements by euro area central bankers during the first years of the European Economic and Monetary Union (EMU).

The second aim of this paper is to examine the role of disagreement. Jansen and De Haan (2006) and Ehrmann and Fratzscher (2005) show that, in recent years, euro area central bankers often voiced contrasting opinions on euro area monetary policy and economic conditions. What, if anything, can market participants learn from these voiced differences of opinion? Does disagreement hamper the markets' understanding of future policy? Or, alternatively, can disagreement be informative? By receiving varying messages, agents may be better able to evaluate the different arguments on which the subsequent decision is based.

A number of recent papers study the relationship between central bank communication and interest rate policy. Pakko (2005) finds that the bias announcements by the Federal Open Market Committee contain useful information for predicting future changes in the federal funds target rate. Lapp and Pearce (2000) reach a similar conclusion with respect to inter-meeting policy changes. Other studies focus on the European Central Bank (ECB). Gerlach (2004) uses 
the editorials of the ECB monthly bulletin to construct quantitative indicators of the ECB's assessment of euro area economic conditions. He finds that models incorporating these indicators can better predict policy decisions than models which only include macroeconomic variables. Rosa and Verga (2005) find that ECB communication can explain changes in market expectations of future policy. This conclusion is based on an analysis of the introductory statements by the ECB president at the press conferences after interest rate decisions. Heinemann and Ullrich (2005) construct an indicator based on the same statements and show that an analysis of ECB rhetoric can improve, but not substitute a Taylor rule model in predicting interest rate changes ${ }^{1}$.

Central banks communicate using various channels, such as press conferences, releases of minutes, monthly bulletins, speeches and interviews. Our analysis differs from previous papers in its use of statements by central bankers as reported by the Bloomberg news-wire. We can thus analyse those central bank comments which would, in all likelihood, reach a large portion of financial market participants. We have collected Bloomberg news reports containing statements by various euro area central bankers for the period 4 January 1999 to 2 May $2002^{2}$. We classify each comment on a ternary scale $(+1,0,-1)$ to construct two indicators of ECB communication: a signal and a dispersion indicator. The signal indicator measures the message of the central bankers to the public. The dispersion indicator measures the extent to which central bankers were in disagreement on a particular topic. We use these indicators in an ordered probit regression framework whilst using Taylor rule models as a benchmark. We test for the effects of disagreement by including dispersion indicators as additional variables into our communication models. Finally, we decompose the signal indicators into a component driven by economic developments and a residual component. This enables us to study the relationship between macroeconomic variables and communication in more detail.

Our results are as follows. We show that comments by euro area central

\footnotetext{
${ }^{1}$ Siklos and Bohl (2005) study the Bundesbank. They find that, between 1982 and 1998, the Bundesbank used communication as a separate instrument, complementary to the interest rate instrument.

${ }^{2}$ We did not record reports on the ECB press conferences after rate decisions; the comments at the press conference are analysed by Heinemann and Ullrich (2005) and Rosa and Verga (2005).
} 
bankers contain information on future ECB interest rate decisions. During the first years of the EMU, comments by ECB Executive Board members and high-level Bundesbank policy-makers were more informative than comments by national central bank presidents. However, models using only communication indicators are outperformed by straightforward Taylor rule models. More importantly, the information content of the statements was mainly a reflection of macroeconomic developments. If we control for this effect, communication has little value added for explaining future decisions. We also show that differences of opinion were informative when they concerned the outlook for economic growth. Finally, we find that the ECB used communication especially to signal interest rate increases.

The remainder of this paper is structured as follows: section 2 discusses our methodology, while section 3 presents the data. Section 4 presents the ordered probit regression results, whereas section 5 discusses the predictive power of different specifications. Section 6 has results for the decomposed communication. Section 7 gives our conclusions.

\section{Methodology}

\subsection{Communication and interest rate decisions}

How do agents form expectations of future interest rate decisions? A logical step would be to use the rule suggested by Taylor (1993) to analyse the relationship between decisions and macroeconomic developments. According to the Taylor rule, the interest rate that the central bank targets $\left(i_{t}^{*}\right)$ is a linear function of inflation $\left(\pi_{t}\right)$, the equilibrium real interest rate $\left(r^{*}\right)$, the difference between actual inflation and target inflation $\left(\pi_{t}-\pi^{*}\right)$ and the output gap $y_{t}$. As the ECB attributes an important role to developments in the money supply, it makes sense to include the difference between actual money growth and the target level for the growth of the money supply $\left(m_{t}-m^{*}\right)$ in the Taylor rule (see also Gerlach (2004) and Heinemann and Ullrich (2005)). The target interest rate is defined as follows:

$$
i_{t}^{*}=\pi_{t}+r^{*}+\alpha_{1}\left(\pi_{t}-\pi^{*}\right)+\alpha_{2} y_{t}+\alpha_{3}\left(m_{t}-m^{*}\right)
$$


Judd and Rudebusch (1998) suggest to allow for a smooth adjustment of the actual interest rate to the target level:

$$
\Delta i_{t}=\gamma\left(i_{t}^{*}-i_{t-1}\right)+\rho \Delta i_{t-1}
$$

By substituting equation (1) into equation (2) and re-writing, we obtain:

$$
\Delta i_{t}=a_{0}+a_{1} \pi_{t}+a_{2} y_{t}+a_{3} m_{t}-\gamma i_{t-1}+\rho \Delta i_{t-1}
$$

where $a_{0}=\gamma\left(r^{*}-\alpha_{1} \pi^{*}-\alpha_{3} m^{*}\right)$.

As the ECB changes interest rates in steps that are multiples of 25 basis points we use ordered probit models. We model the interest rate decision $\Delta i_{t}$ as a ternary variable which has the value 0 if interest rates were kept constant, +1 if interest rates were raised and -1 if interest rates were lowered ${ }^{3}$. Using (3) we specify an index function as follows:

$$
\Delta i_{t}^{*}=a_{1} \pi_{t}+a_{2} y_{t}+a_{3} m_{t}-\gamma i_{t-1}+\rho \Delta i_{t-1}+\epsilon_{t}
$$

where $\Delta i_{t}^{*}$ is a latent continuous random variable representing the preferred interest rate change. We assume that the policy decision is characterised by threshold behaviour: the central bank will change the interest rate if $\Delta i_{t}^{*}$ passes two unobservable thresholds $\tau_{1}$ and $\tau_{2}$ :

$$
\Delta i_{t}=\left\{\begin{aligned}
-1 & : \quad \Delta i_{t}^{*} \leq \tau_{1} \\
0 & : \quad \Delta i_{t}^{*} \in\left(\tau_{1}, \tau_{2}\right) \\
1 & : \quad \Delta i_{t}^{*} \geq \tau_{2}
\end{aligned}\right.
$$

Assuming that $\epsilon_{t}$ follows a standard normal distribution, we can write the probabilities of the different outcomes as follows:

$$
\begin{gathered}
\operatorname{Pr}\left[\Delta i_{t}=-1 \mid z_{t}\right]=\Phi\left(\tau_{1}-z_{t}^{\prime} \beta\right) \\
\operatorname{Pr}\left[\Delta i_{t}=0 \mid z_{t}\right]=\Phi\left(\tau_{2}-z_{t}^{\prime} \beta\right)-\Phi\left(\tau_{1}-z_{t}^{\prime} \beta\right) \\
\operatorname{Pr}\left[\Delta i_{t}=1 \mid z_{t}\right]=1-\Phi\left(\tau_{2}-z_{t}^{\prime} \beta\right)
\end{gathered}
$$

\footnotetext{
${ }^{3}$ Our analysis focuses on the direction of the interest rate changes. One could also take the size of the changes into account, but, in our case, we would be left with low numbers of observations in the respective categories.
} 
where $\Phi$ denotes the cumulative standard normal distribution and $z_{t}$ is a vector with the explanatory variables $\left[\pi_{t}, y_{t}, m_{t}, i_{t-1}, \Delta i_{t-1}\right]$. This ordered probit model can now be estimated using maximum likelihood procedures (see Maddala (1983)).

We first estimate an ordered probit model using (4) to determine the relationship between decisions and macroeconomic variables. By doing this, we obtain a benchmark with which we can compare our results for communication. Next, we estimate an ordered probit model in which we only use our signal indicators as explanatory variables. In other words, we replace each variable in the Taylor rule by the voiced opinion of the ECB on this variable as follows:

$$
\Delta i_{t}^{*}=b_{1} S_{t}^{i}+b_{2} S_{t}^{\pi}+b_{3} S_{t}^{y}+b_{4} S_{t}^{m}+\epsilon_{t}
$$

where $S_{t}^{x}$ denotes the signal indicator on interest rates, inflation, economic growth and M3, respectively and $\epsilon_{t} \sim N(0,1)$.

We also test whether it matters whether central bankers are in agreement on the topics which they discuss. Ehrmann and Fratzscher (2005) and Jansen and De Haan (2006) show that euro area central bankers have, at times, been inconsistent in their comments to financial markets in recent years. If central bankers voice different opinions on future policy or the economic outlook, does this hamper the markets' understanding of future policy? Or, alternatively, is disagreement informative? By receiving varying messages, the markets may be able to see the different arguments on which the subsequent decision is based. We test for the effects by introducing indicators that measure disagreement as additional explanatory variables in (8). The model then reads as:

$$
\Delta i_{t}^{*}=b_{1} S_{t}^{i}+b_{2} S_{t}^{\pi}+b_{3} S_{t}^{y}+b_{4} S_{t}^{m}+b_{5} D_{t}^{i}+b_{6} D_{t}^{\pi}+b_{7} D_{t}^{y}+b_{8} D_{t}^{m}+\epsilon_{t}
$$

where $D_{t}^{x}$ denotes the dispersion indicator on interest rates, inflation, economic growth and M3, respectively and $\epsilon_{t} \sim N(0,1)$.

As a part of the analysis, we pay attention to the group of officials who make statements. Comments by certain officials may be more informative than comments by others. We can easily test for this by constructing communication indicators using only statements by certain groups of central bankers. 


\subsection{Measures of ECB communication}

We use two indicators to measure communication : one measures the signal in ECB communication, whereas the other measures the dispersion of ECB communication. We gathered the data on ECB communication by searching the Bloomberg news-wire for statements by euro area central bankers on euro area monetary policy and economic conditions. The search was performed by scanning the news headlines for keywords such as names of central bankers or issues related to monetary policy. If the headline contained such a word, we read the underlying news report to determine whether it contained statements by central bankers. We focused on statements on interest rates, euro area inflation and economic growth and M3. Having collected the relevant reports, we recorded i) who made statements, ii) what topics were commented on, and iii) what opinion was expressed with regard to the items under ii). Regarding this latter point, we coded each comment on a ternary scale. We determined whether a variable is projected to go downwards, remain at its current level or go upwards. In the first case, the comment would receive a value of -1 , in the second case it would receive a value of 0 and in the final case it would receive a value of +1 . For example, comments projecting lower levels of risk with respect to euro area inflation would receive a -1 , statements with a positive outlook for economic growth would receive a +1 , while comments suggesting constant interest rates would receive a 0 .

Based on our ternary classification, we constructed a series of ECB signals per category on a daily basis as follows:

$$
S_{\tau}^{x}=\left[n_{\tau}^{+}-n_{\tau}^{-}\right] * \frac{9.5}{\left(D_{\tau}+1\right)}
$$

where $n_{\tau}^{+}$denotes the number of statements with the value +1 on day $\tau, n_{\tau}^{-}$ denotes the number of statements with the value $-1, \mathrm{D}$ denotes the number of days to the next interest decision and $x$ is either interest rates, inflation, economic growth or M3. We multiply by the fraction $\frac{9.5}{(D+1)}$ to take into account that statements made closer to interest rate decisions may have more impact. Therefore, we divide by the distance to the next ECB interest decision. Subsequently, in order to re-scale, we multiply by the average number of days to a decision $^{4}$.

\footnotetext{
${ }^{4}$ In some cases, there are reports of statements on the days of interest rate decisions. To
} 
To construct the indicators $S_{t}^{x}$, we first sum $S_{\tau}^{x}$ over the periods between interest rate decisions. As the periods between rate decisions were not of equal length in the sample, we divided the sum of the daily signals by the number of days between the time of the decision and the former decision. To re-scale, we multiply the result by the average number of days between rate decisions, the average being equal to 15.25. We calculated the indicators using all ECB comments on a particular topic ${ }^{5}$. In addition, we constructed the indicators for different groups of central bankers.

To measure disagreement in ECB communication, we use the dispersion indicator introduced in Jansen and De Haan $(2006)^{6}$. The dispersion indicator is based on our ternary classification of all comments on a particular topic. We construct $D_{t}^{x}$ as the total distance between the scores divided by the maximum total distance between the scores. Because the indicator is scaled on a maximum score, it has the attractive feature that it ranges between 0 (no disagreement) and 1 (complete disagreement). It can be calculated as follows:

$$
D_{t}^{x}=\frac{n_{t}^{+} n_{t}^{0}+n_{t}^{0} n_{t}^{-}+2 n_{t}^{+} n_{t}^{-}}{0.5\left(n^{2}-d\right)}
$$

where $d$ equals 1 if $n$ is odd and zero otherwise, $x$ is either inflation, inflation, economic growth or M3 and $n_{t}^{+}$denotes the number of statements with the value +1 in inter-meeting periods, $n_{t}^{-}$denotes the number of statements with the value -1 and $n_{t}^{0}$ denotes the number of statements with the value 0 .

For example, assume that in an inter-meeting period there were three comments by ECB officials on interest rates. Of these three comments, one suggests higher rates are to be expected, whereas the other two are neutral. The scores in this case would be 1,0 and 0 . In the example, the total distance between the statements equals 2 and, as the maximum total distance equals $4, D_{t}^{i}$ equals 0.5 . Once again, we compute the indicator for different groups of central bankers.

prevent that we have to divide by zero, we add 1 to $D$. The average number of days to decisions is actually 8.5 , but here we also added the 1 .

${ }^{5} \mathrm{On}$ a priori grounds, we prefer to take the timing of the statement into account when constructing the indicator. The patterns of the indicators are very similar if we do not weigh by the distance to the next decision or the number of days between decisions.

${ }^{6}$ This indicator is also used in Ehrmann and Fratzscher (2005). 


\section{Data}

We study the period from 4 January 1999 to 2 May 2002. During this period, the ECB made 75 interest rate decisions. The first was made on 7 January 1999, the last on 2 May 2002. On 12 occasions interest rates were changed: there were 5 downward interest rate changes and 7 upward changes. Searching Bloomberg, we found 925 reports containing comments by euro area central bankers during the sample period. We have data on statements by three different groups: members of the ECB Executive Board (EB), national central bank (NCB) presidents and high-level policymakers from the Bundesbank ${ }^{7}$. There were 277 statements on interest rates, 394 on inflation, 356 on economic growth and 98 on M3. EB members made 93 statements on interest rates, 149 on inflation, 157 on economic growth and 32 on M3. For NCB presidents, these figures are 135, 210, 174 and 49. For Bundesbank officials, the figures are 49, 35,25 and 17. Table 1 gives a summary of the data, showing the percentage of statements per topic for the three groups of central bankers and the full sample. As may be expected, most statements on interest rates were neutral. In contrast, most statements on economic growth were optimistic in nature. Finally, it seems that Bundesbank officials were less optimistic on growth, more inclined to point towards rises in M3 and less neutral on interest rates.

Figure 1 shows the development in the ECB main refinancing rate (solid line) and the signal indicator on interest rates (column) over the sample period. The dates shown correspond to ECB rate changes. In some cases, the signal and the decision corresponded perfectly. For example, the signal indicator for the meeting on 3 February 2000 has a value of 13 . At this meeting, interest rates were increased by 25 basis points. However, in other cases, the correspondence is far from perfect. Figure 2 shows the relationship between dispersion in communication on interest rates (column) and the main refinancing rate (solid line).

\footnotetext{
${ }^{7}$ The inclusion of this latter group may be understood by remembering that there consisted a large degree of uncertainty concerning the implementation of the ECB monetary policy strategy at the beginning of the EMU. This created an incentive for financial market participants to obtain as much information as possible. The Bundesbank seemed a natural choice in this respect, as is illustrated by the following quote from a financial analyst: 'Bundesbank council members are probably as close as one can get to being a fly on the ECB's wall'(Bloomberg, 1 August 2001).
} 
In most cases, when there is disagreement among central bankers, the dispersion indicator is equal to or higher than 0.50. Disagreement is mostly visible in 1999 and the first half of 2000 and towards the end of the sample period.

To estimate the Taylor rule models, we use monthly euro area data on inflation, industrial production (excluding construction) and money growth as published in the ECB monthly bulletin ${ }^{8}$. We take data on ECB policy decisions from the ECB web-site. We choose the monthly bulletin as a data source in order to approximate the information available to policy makers at the time of their decisions as closely as possible (see also Coenen, Levin and Wieland (2005) and Sauer and Sturm (2006)). The Monthly Bulletin reports euro area data as released by Eurostat with a time lag. For inflation, this lag is mostly two months, for money growth it is three months and for industrial production it is three to four months. For inflation, we use the most recent value of the year-on-year change in HICP inflation. For money growth, we use the most recent reported value of the three-month moving average of annualised growth in M3, as this is the value that the ECB is supposed to target.

To proxy the output gap, we use two measures. Firstly, we use the published series of industrial production (excluding construction). There are only a limited number of months reported in each monthly bulletin. Therefore, we add historical Eurostat data for the months that are not reported, starting in 1985:1. We calculate the output gap as the difference between the natural logarithm of the index of industrial production $(1995=100)$ and the trend of this series, where we use a HP filter for de-trending. As we use monthly data, we use a smoothing parameter of 14,400 . The second output gap measure is based on the economic sentiment indicator (ESI) as published by the European Commission (see also Gerlach (2004) and Sauer and Sturm (2006)). The ESI is based on confidence indicators for consumers, the retail sector, the construction sector and the manufacturing sector. In the case of the ESI, we use data obtained from the European Commission web-site ${ }^{9}$. We use the difference between the value of the ESI in a particular month and a long-term average. The long-term average

\footnotetext{
${ }^{8}$ As there were two interest rate decisions per month until November 2001, the monthly values are, in most cases, used to explain two subsequent decisions.

${ }^{9}$ http://europa.eu.int/comm/economy finance/indicators/business consumer surveys/bcsseries en.htm. At this point in time, the ESI also incorporates an indicator for the services sector.
} 
is calculated using a rolling window consisting of the 144 preceding months.

\section{Results for ordered probit regressions}

Table 2 shows full sample results for the ordered probit models. Columns (1) and (2) show results for our two specifications of the Taylor rule, where the first column uses data on industrial production and the second column uses the sentiment indicator. The coefficients are comparable for both specifications. The coefficient for HICP inflation is between 1.16 and 1.26 and significant at the $10 \%$ level in both cases. The coefficient for both industrial production and the ESI are highly significant $(\mathrm{p}<0.01)$. The coefficient for the lagged level of the refinancing rate is negative and significant, which points to smoothing in interest rate setting. Finally, the pseudo- $R^{2}$ equals 0.25 for the first model and 0.38 for the second model.

If we replace the variables in the Taylor specification by communication variables, we find, firstly, that the fit of the model deteriorates substantially: the pseudo- $R^{2}$ drops to 0.10 (column (3)). Furthermore, the only variable for which we find a significant coefficient is the ECB signal on interest rates. If we condition the results on the level of dispersion (column (4)), the fit of the model improves, albeit slightly, to 0.17 . Our estimate for the coefficient of the signal on interest rates is comparable to the one we found before, but now, in addition, we find a significant coefficient for the dispersion indicator on economic growth. However, this model based on communication has a worse fit than both Taylor rule models.

Table 3 shows estimation results for groups of central bankers. We show results for EB members (column (1) and (2)), NCB presidents (columns (3) and (4)) and Bundesbank officials (columns (5) and (6)). We show estimates with and without dispersion indicators. When comparing these estimates, we find that in all three cases the fit of the model is better when we include both signal and dispersion indicators ${ }^{10}$. For the EB members and the NCB presidents, this is due to the dispersion indicator on economic growth, whereas for the EB members the dispersion indicator on interest rates is also significant. Comparing

\footnotetext{
${ }^{10}$ We do not use the dispersion indicators for M3, as the number of observations different from zero is very small $(\leq 7)$
} 
the models for the different groups, we find the best fit for the EB members and the Bundesbank officials. In both cases, this is mainly due to the signal indicator on interest rates, which are highly significant in both cases. For the NCB presidents, none of the signal indicators is significantly different from zero at the $10 \%$ level.

To test for the effects of dispersion, we performed likelihood ratio tests. The unrestricted models are specifications with signal and dispersion indicators, whereas the restricted model restricts the coefficients for one or all of the dispersion indicators to be equal to zero. Table 4 has results. Firstly, except for the case of the EB members, we cannot reject the hypothesis that the three coefficients of the dispersion indicators are different from zero. However, if we only test for the dispersion indicator on growth, the story changes. Now, the Bundesbank is the only case for which we cannot reject the null. For the full sample and the NCB presidents we reject the null, whereas for the EB members we can reject the null that none of the three indicators matter. In other words, disagreement can be linked to interest rate decisions, especially if the differences of opinion concern the economic outlook.

This is further corroborated by studying marginal effects. Table 5 shows results for three specifications: the Taylor rule with industrial production, the Taylor rule with the sentiment indicator and our communication model. All marginal effects are evaluated at sample means. The effects for the variables in the Taylor rule are, in general, larger than the effects of the communication variables. This holds in particular for the signal indicators. The only indicator for which the marginal effects are different from zero is the indicator on interest rates. In this case, the sign of the effect is consistent with expectations: a higher interest rate indicator has a positive effect on the probability of an interest rate rise and a negative effect on the probability of an interest rate lowering. Concerning the dispersion indicators, we only find a significant effect for the indicator on economic growth. The sign of the effect is, once again, noteworthy: higher dispersion on growth increases the probability of a lower interest rate and decreases the probability of higher interest rates. 


\section{Evaluating predictive power}

To what extent are the estimated models able to re-produce the timing and the nature of ECB interest rate decisions? To examine this, we determine the decision with the highest level of probability according to our model and compare this prediction with the actual outcome. Table 6 has the full sample results, while table 7 has group results. The second column of both tables lists the actual distribution of rate decisions during the sample period. Under the heading distribution, we list the distribution of the predicted decisions. Under the heading \% correct, we list the fraction of correctly predicted decisions, correctly predicted changes and correctly predicted downward and upward changes.

What emerges from tables 6 and 7 is the inability of our models to predict downward interest rate changes. Almost without exception, the models do not predict any downward changes, and, as a result, predict none of the 5 downward changes correctly. The most balanced and, for that matter, accurate model is the Taylor rule model using the ESI data (table 6, column 4). The model predicts both downward and upward changes. In all, it predicts 1 out of 3 changes correctly. Why are upward rate changes more predictable? Figure 1 may hold the explanation. There are more positive signals than negative signals. Moreover, the positive signals are larger in absolute value. In general, it is easier for a central bank to lower rates than to raise them. It would, therefore, be likely that this is reflected in more active communication before upward interest rate changes. During the first years of EMU, this explanation seems to be true for the ECB.

Furthermore, we find that dispersion helps to make better predictions. Comparing the last two columns of table 6 shows that the inclusion of dispersion indicators in the model leads to better predictions than if we only use signal indicators. However, the result is still not as good as for the case of the Taylor rule using the ESI. We find similar results if we focus on the different groups. The models with dispersion indicators allow for somewhat better forecasting, but do not outperform straightforward Taylor rule models. Finally, we find, as would be expected on the basis of the results in table 3 , that communication by EB members and high-level Bundesbank officials was more informative than comments by NCB presidents. The models using NCB communication always 
predict 'no change'. Models using both signal and dispersion indicators correctly predict $16.7 \%$ of the changes for the $\mathrm{EB}$ and $25 \%$ of the changes for the Bundesbank.

\section{Decomposing communication}

Until now, the results suggest that analysing communication or analysing macroeconomic variables will yield, more or less, similar results. We have, however, still not explicitly addressed the relationship between macroeconomic variables and ECB communication. Therefore, we decompose the signal indicators of ECB communication in two components: one component driven by macroeconomic developments and one residual component. We do this by running OLS regressions of each signal indicator on the variables in the Taylor rule:

$$
S_{t}^{x}=\beta_{0}+\beta_{1} \pi_{t}+\beta_{2} y_{t}+\beta_{3} m_{t}+\beta_{4} i_{t-1}+\beta_{5} \Delta i_{t-1}+\psi_{t}^{x}, \psi_{t}^{x} \sim N\left(0, \sigma_{\psi^{x}}^{2}\right)
$$

where $x$ is either interest rates, inflation, economic growth or money supply. We interpret the predicted values from this regression, $\hat{S}_{t}^{x}$, as the part of communication which is driven by recent macroeconomic developments. It is the communication that an observer of the ECB would expect on the basis of the state of the economy. We use the residuals as a measure for the part of communication which is not a reflection of economic developments. We use both measures in an ordered probit framework. First, we study effects of the predicted values on interest decisions using the following index function:

$$
\Delta i_{t}^{*}=c_{1} \hat{S}_{t}^{i}+c_{2} \hat{S}_{t}^{\pi}+c_{3} \hat{S}_{t}^{y}+c_{4} \hat{S}_{t}^{m}+\nu_{t}, \nu_{t} \sim N(0,1)
$$

Next, we estimate an ordered probit model using the residuals from (12):

$$
\Delta i_{t}^{*}=c_{5} \psi_{t}^{i}+c_{6} \psi_{t}^{\pi}+c_{7} \psi_{t}^{y}+c_{8} \psi_{t}^{m}+v_{t}, v_{t} \sim N(0,1)
$$

where $\psi_{t}^{x}$ denote the residuals for interest rates, inflation, output and M3, respectively. Using (13) and (14) we can assess which part of communication is informative by assessing the significance of the coefficients.

Table 8 presents the full sample results for the OLS regressions of the signal indicators on the macroeconomic variables ${ }^{11}$. We see that the signals are mainly

\footnotetext{
${ }^{11}$ We only present results using the sentiment indicator. Results when using the output gap
} 
determined by developments in economic sentiment. There is also a strong relationship to the lagged level of the main refinancing rate. Developments in inflation and money growth do not seems to be significant determinants of the signal. Table 9 presents the results for the ordered probit model based on (13), while table 10 presents the results for estimating the model based on (14). The contrast is striking. Table 9 shows that predicted communication is useful in explaining interest rate decisions. This is due to the fact that past economic developments are useful in explaining policy, as can be seen from the first two columns of table 2. If we use filtered communication, the significant results disappear, with the exception of the signal on economic growth by the Bundesbank. So, there is little evidence that non-macro driven communication is informative with respect to ECB interest rate decisions ${ }^{12}$. This leads to the conclusion that this particular form of communication is informative, but that it primarily provides similar information as recent economic developments.

\section{Conclusions}

This paper studies the relationship between central bank communication and subsequent interest rate decisions using comments by euro area central bankers. In contrast to the proverb, we find that a word to the wise is not enough. Models that only use communication indicators do not outperform straightforward Taylor rule models. More importantly, we show that the information in communication was mainly a reflection of macroeconomic developments. If we filter communication for this effect, communication has little value added for explaining future decisions. For the European Central Bank, of course, a learning process may have occurred. Our sample period ends in May 2002. In recent years, ECB communication may have improved, in this respect. Nevertheless, the observed pattern raises interesting issues. What, for example, is the use of central bank watching, when similar information may be obtained by directly analysing economic developments?

are similar. We also do not show results per group, as results are similar. Results available upon request from the corresponding author.

${ }^{12}$ The models are also poor predictors of future decisions: they predict 'no change' for every decision. Results available upon request. 
Our results also suggest that agents may learn from disagreement among central bankers, especially when it concerns the outlook for economic growth. We show that disagreement on this issue and decisions are correlated. In addition, using indicators for disagreement improves the predictive power of communication models. Does this automatically imply that showing disagreement is beneficial? Not necessarily. We have not taken any detrimental effects that disagreement may have into account. To take a simple example, what if disagreement increases volatility in financial markets and thus, potentially, uncertainty? Future research should consider the possible positive and negative effects of dispersion explicitly.

We document differences in the information content of comments by different groups of central bankers. During the first years of the European Economic and Monetary Union, comments by ECB Executive Board members and highlevel Bundesbank officials had a larger information content than those by NCB presidents. Whether comments by the Bundesbank continue to be of great importance in recent years remains a matter to be determined empirically. We would expect the importance of this group to have declined over time.

Finally, we show that the ECB used communication more actively when upward interest rate changes were concerned. This is rationalized by the fact that downward interest rate changes will, in all likelihood, receive a warmer welcome from the public than upward changes. It would be interesting to study this issue in more detail for other major central banks, such as the US Federal Reserve or the Bank of England.

\section{Acknowledgements}

We thank Het Financieele Dagblad for the use of Bloomberg. This paper greatly benefited from comments by seminar participants at De Nederlandsche Bank. Any errors are our own responsibility. Views expressed in this paper do not necessarily coincide with those of De Nederlandsche Bank. 


\section{References}

Bernanke, B., V. Reinhart and B. Sack (2004), 'Monetary policy alternatives at the zero bound: an empirical assessment', Brookings Papers on Economic Activity 2, 1-100.

Coenen, G., A. Levin and V. Wieland (2005), 'Data uncertainty and the role of money as an information variable for monetary policy', European Economic Review 49(4), 975-1006.

Ehrmann, M. and M. Fratzscher (2005), 'Communication and decision-making by central bank committees: Different strategies, same effectiveness?', European Central Bank Working Paper no. 488.

Gerlach, S. (2004), 'Interest rate setting by the ECB: words and deeds', CEPR discussion paper series no. 4775 .

Gürkaynak, R. S., B. Sack and E. T. Swanson (2005), 'Do actions speak louder than words? The response of asset prices to monetary policy actions and statements', International Journal of Central Banking 1(1), 55-93.

Heinemann, F. and K. Ullrich (2005), 'Does it pay to watch central bankers' lips? The information content of ECB wording', mimeo.

Jansen, D. and J. De Haan (2006), 'Look who's talking: ECB communication during the first years of EMU', International Journal of Finance and Economics, forthcoming.

Judd, J.P. and G.D. Rudebusch (1998), 'Taylor's rule and the Fed: 1970 - 1997', Federal Reserve Board of San Francisco Economic Review 3, 3-16.

Kohn, D.L. and B. Sack (2003), 'Central bank talk: does it matter and why?', Finance and Economics Discussion Series Washington: Board of Governors of the Federal Reserve System no. 55.

Lapp, John S. and Douglas K. Pearce (2000), 'Does a bias in FOMC policy directives help predict intermeeting policy changes?', Journal of Money, Credit, and Banking 32(3), 435-441. 
Maddala, G.S. (1983), Limited-dependent and qualitative variables in econometrics, Cambridge: Cambridge University Press.

Pakko, Michael R. (2005), 'On the information content of asymmetric FOMC policy statements: evidence from a Taylor-rule perspective', Economic Inquiry 43(3), 558-569.

Rosa, C. and G. Verga (2005), 'Is ECB communication effective?', Centre for Economic Performance discussion paper no. 682.

Sauer, S. and J.E. Sturm (2006), 'Using Taylor rules to understand ECB monetary policy', German Economic Review, forthcoming.

Siklos, P.L. and M.T. Bohl (2005), 'Do words speak louder than actions? The conduct of monetary policy at the Bundesbank', Journal of Macroeconomics, forthcoming.

Taylor, J. B. (1993), 'Discretion versus policy rules in practice', CarnegieRochester Conference Series on Public Policy 39, 195-214. 
Figure 1: Developments in ECB main refinancing rate and signal on interest rates

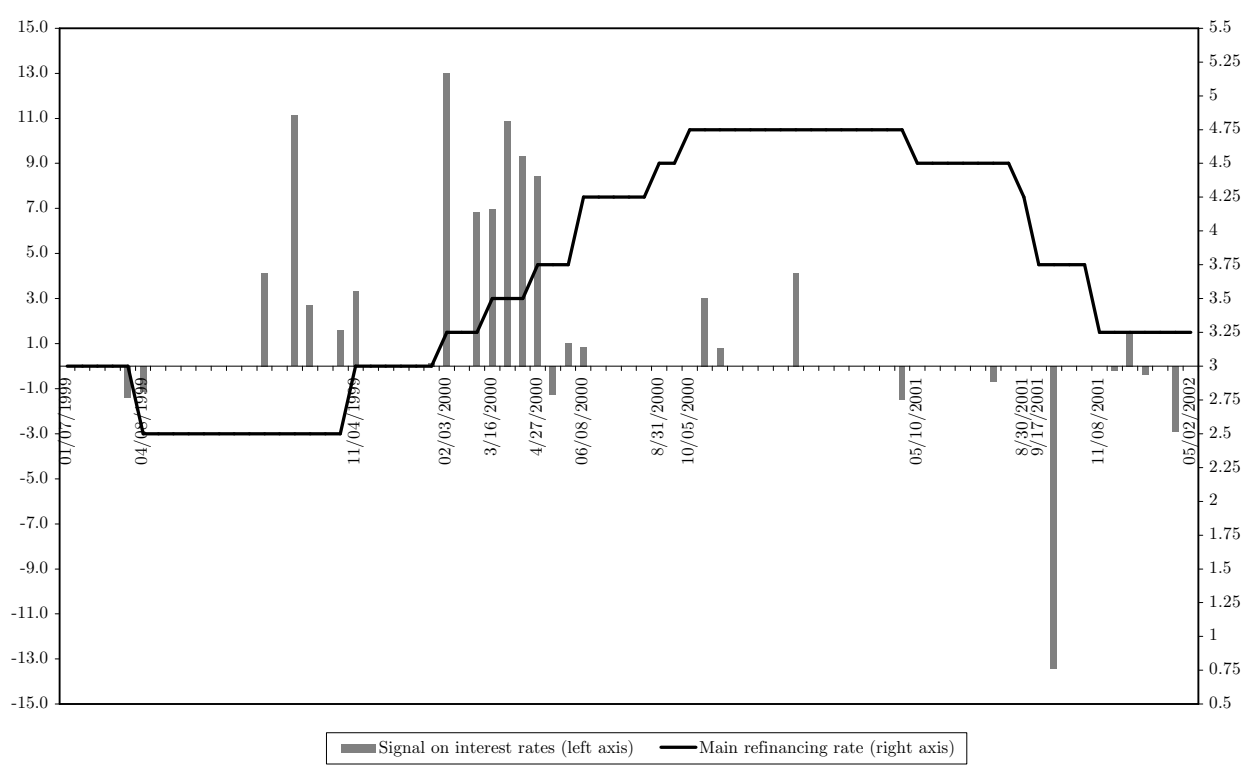

This figure describes developments in the ECB main refinancing rate and the signal on interest rates between 4 January 1999 and 2 May 2002. The dates on the horizontal axis correspond to the timing of ECB interest rate changes and the endpoints of the sample period $(M M D D Y Y Y Y)$. The left axis shows the signal on interest rates, the right axis shows the level of the main refinancing rate. 
Figure 2: Developments in ECB main refinancing rate and disagreement on interest rates

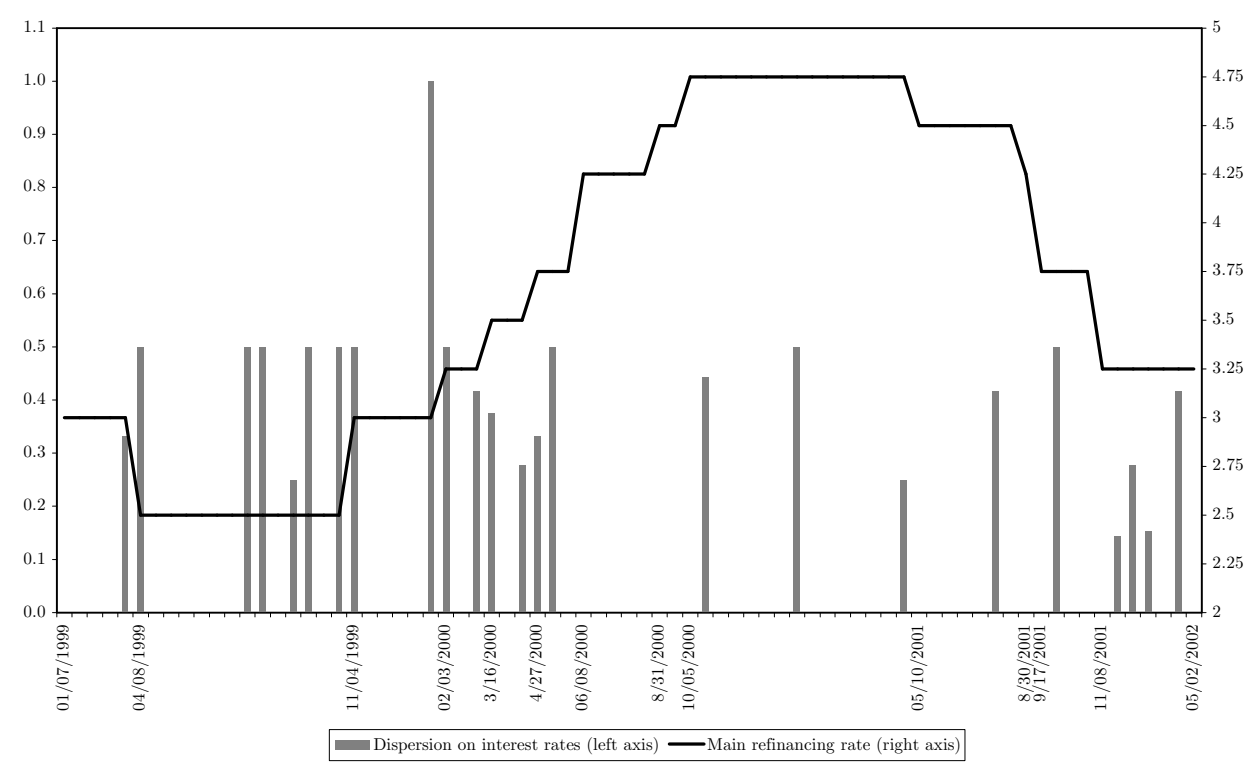

This figure describes developments in the ECB main refinancing rate and dispersion on interest rates. between 4 January 1999 and 2 May 2002. The dates on the horizontal axis correspond to the timing of ECB interest rate changes and the endpoints of the sample period $(M M D D Y Y Y Y)$. The left axis shows the dispersion on interest rates, the right axis shows the level of the main refinancing rate. 
Table 1: Ternary classification of ECB statements

\begin{tabular}{ll|c|c|c|c}
\hline \hline \multicolumn{2}{c|}{ Comment on: } & Executive Board & NCB presidents & BuBa $^{*}$ & Full sample \\
\hline Rates: & Up & 12.9 & 14.1 & 18.4 & 14.4 \\
& Neutral & 83.9 & 82.2 & 71.4 & 80.9 \\
Down & 3.2 & 3.7 & 10.2 & 4.7 \\
\hline Inflation: Up & 23.5 & 24.3 & 28.6 & 24.2 \\
& Neutral & 47.7 & 39.5 & 45.7 & 43.3 \\
& Down & 28.9 & 36.2 & 25.7 & 32.5 \\
\hline Growth: & Up & 82.8 & 72.4 & 52.0 & 75.4 \\
& Neutral & 7.0 & 12.1 & 16.0 & 10.1 \\
& Down & 10.2 & 15.5 & 32.0 & 14.6 \\
\hline M3: & 31.3 & 24.5 & 41.2 & 29.6 \\
& Up & 40.8 & 29.4 & 37.8 \\
& Neutral & 37.5 & 34.7 & 29.4 & 32.7 \\
\hline \hline
\end{tabular}

Notes: * Bundesbank officials excluding the President.

The entries in this table are the percentages of the total number of statements per category per group. The sample period is 4 January 1999 to 2 May 2002. 
Table 2: Full sample results for ordered probit models

\begin{tabular}{|c|c|c|c|c|}
\hline & $\begin{array}{c}(1) \\
\text { Taylor }\end{array}$ & $\begin{array}{c}(2) \\
\text { Taylor }\end{array}$ & $\begin{array}{c}(3) \\
\text { ECB signal }\end{array}$ & $\begin{array}{c}(4) \\
\text { ECB signal \& dispersion }\end{array}$ \\
\hline HICP inflation & $\begin{array}{l}1.26^{*} \\
(0.66)\end{array}$ & $\begin{array}{l}1.16^{*} \\
(0.66)\end{array}$ & - & - \\
\hline Ind. production & $\begin{array}{c}0.95 * * * \\
(0.25)\end{array}$ & - & - & - \\
\hline ESI & - & $\begin{array}{c}2.56^{* * *} \\
(0.65)\end{array}$ & - & - \\
\hline M3 & $\begin{array}{c}0.13 \\
(0.26)\end{array}$ & $\begin{array}{l}0.63^{*} \\
(0.35)\end{array}$ & - & - \\
\hline$i_{t-1}$ & $\begin{array}{c}-2.07^{* *} \\
(0.81)\end{array}$ & $\begin{array}{c}-1.45^{* *} \\
(0.72)\end{array}$ & - & - \\
\hline$\Delta i_{t-1}$ & $\begin{array}{r}0.09 \\
(0.43) \\
\end{array}$ & $\begin{array}{l}-0.75 \\
(0.57) \\
\end{array}$ & - & - \\
\hline Signal & & & & \\
\hline$\overline{\text { Interest }}$ rates & - & - & $\begin{array}{c}0.17^{* *} \\
(0.07)\end{array}$ & $\begin{array}{c}0.15^{* *} \\
(0.07)\end{array}$ \\
\hline Inflation & - & - & $\begin{array}{l}-0.03 \\
(0.02)\end{array}$ & $\begin{array}{l}-0.03^{*} \\
(0.02)\end{array}$ \\
\hline Economic growth & - & - & $\begin{array}{l}-0.02 \\
(0.05)\end{array}$ & $\begin{array}{l}-0.03 \\
(0.07)\end{array}$ \\
\hline M3 & - & - & $\begin{array}{c}0.02 \\
(0.06)\end{array}$ & $\begin{array}{c}0.03 \\
(0.06)\end{array}$ \\
\hline \multicolumn{5}{|l|}{ Dispersion } \\
\hline$\overline{\text { Interest rates }}$ & - & - & - & $\begin{array}{c}0.40 \\
(0.98)\end{array}$ \\
\hline Inflation & - & - & - & $\begin{array}{c}0.73 \\
(0.47)\end{array}$ \\
\hline Economic growth & - & - & - & $\begin{array}{c}-1.03^{* *} \\
(0.51)\end{array}$ \\
\hline M3 & - & - & - & $\begin{array}{l}-0.83 \\
(1.00)\end{array}$ \\
\hline$\tau_{1}$ & -6.74 & -0.93 & -1.49 & -1.73 \\
\hline$\tau_{2}$ & -2.93 & 4.12 & 1.58 & -1.60 \\
\hline Log pseudo-L & -30.94 & -25.65 & -36.99 & -34.13 \\
\hline Pseudo- $R^{2}$ & 0.25 & 0.38 & 0.10 & 0.17 \\
\hline
\end{tabular}

Note: This table gives results for ordered probit regression models of ECB interest decisions. The sample period is 4 January 1999 to 2 May 2002. Standard errors in parentheses, */**/** denotes significance at the 10/5/1\% level. We use Hubert-White robust estimates of variance in all cases. 
Table 3: Results for groups of central bankers

\begin{tabular}{|c|c|c|c|c|c|c|}
\hline & \multicolumn{2}{|c|}{$\underline{\text { Executive Board }}$} & \multicolumn{2}{|c|}{$\underline{\mathrm{NCB} \text { presidents }}$} & \multicolumn{2}{|c|}{$\underline{\text { Bundesbank officials }}$} \\
\hline & (1) & (2) & (3) & (4) & (5) & (6) \\
\hline \multicolumn{7}{|l|}{ Signal } \\
\hline Interest rates & $\begin{array}{c}0.69^{* * *} \\
(0.22)\end{array}$ & $\begin{array}{c}0.89^{* * *} \\
(0.26)\end{array}$ & $\begin{array}{l}-0.04 \\
(0.07)\end{array}$ & $\begin{array}{l}-0.06 \\
(0.09)\end{array}$ & $\begin{array}{c}0.34^{* * *} \\
(0.12)\end{array}$ & $\begin{array}{c}0.32^{* * *} \\
(0.11)\end{array}$ \\
\hline Inflation & $\begin{array}{c}0.02 \\
(0.03)\end{array}$ & $\begin{array}{l}-0.02 \\
(0.03)\end{array}$ & $\begin{array}{c}0.02 \\
(0.02)\end{array}$ & $\begin{array}{c}0.00 \\
(0.02)\end{array}$ & $\begin{array}{c}0.03 \\
(0.05)\end{array}$ & $\begin{array}{c}0.09 \\
(0.12)\end{array}$ \\
\hline Economic growth & $\begin{array}{c}0.06 \\
(0.08)\end{array}$ & $\begin{array}{c}0.13 \\
(0.09)\end{array}$ & $\begin{array}{c}0.08 \\
(0.07)\end{array}$ & $\begin{array}{c}0.10 \\
(0.10)\end{array}$ & $\begin{array}{l}-0.04 \\
(0.07)\end{array}$ & $\begin{array}{c}0.01 \\
(0.07)\end{array}$ \\
\hline \multicolumn{7}{|l|}{ Dispersion } \\
\hline Interest rates & - & $\begin{array}{c}-2.57^{* *} \\
(1.22)\end{array}$ & - & $\begin{array}{l}-1.13 \\
(1.66)\end{array}$ & - & $\begin{array}{l}-1.02 \\
(1.04)\end{array}$ \\
\hline Inflation & - & $\begin{array}{l}-0.39 \\
(0.54)\end{array}$ & - & $\begin{array}{l}-0.15 \\
(0.66)\end{array}$ & - & $\begin{array}{l}-1.21 \\
(1.00)\end{array}$ \\
\hline Economic growth & - & $\begin{array}{c}-1.68^{* *} \\
(0.67) \\
\end{array}$ & - & $\begin{array}{c}-0.96^{*} \\
(0.52) \\
\end{array}$ & - & $\begin{array}{l}-1.03 \\
(0.85) \\
\end{array}$ \\
\hline$\tau_{1}$ & -1.44 & -2.04 & -1.47 & -1.79 & -1.49 & -1.63 \\
\hline$\tau_{2}$ & 1.61 & 1.49 & 1.39 & 1.23 & 1.55 & 1.52 \\
\hline Log pseudo-L & -36.26 & -31.17 & -40.58 & -38.57 & -35.76 & -34.61 \\
\hline pseudo $R^{2}$ & 0.12 & 0.24 & 0.01 & 0.06 & 0.13 & 0.16 \\
\hline
\end{tabular}

Note: This table gives results for ordered probit models of ECB interest decisions using communication indicators per group. The sample period is 4 January 1999 to 2 May 2002. Standard errors in parentheses, */**/*** denotes significance at the 10/5/1\% level. We use Hubert-White robust estimates of variance in all cases. We do not use the dispersion indicators for $\mathrm{M} 3$ due to a low number of observations different from zero. 
Table 4: Likelihood-ratio tests for dispersion

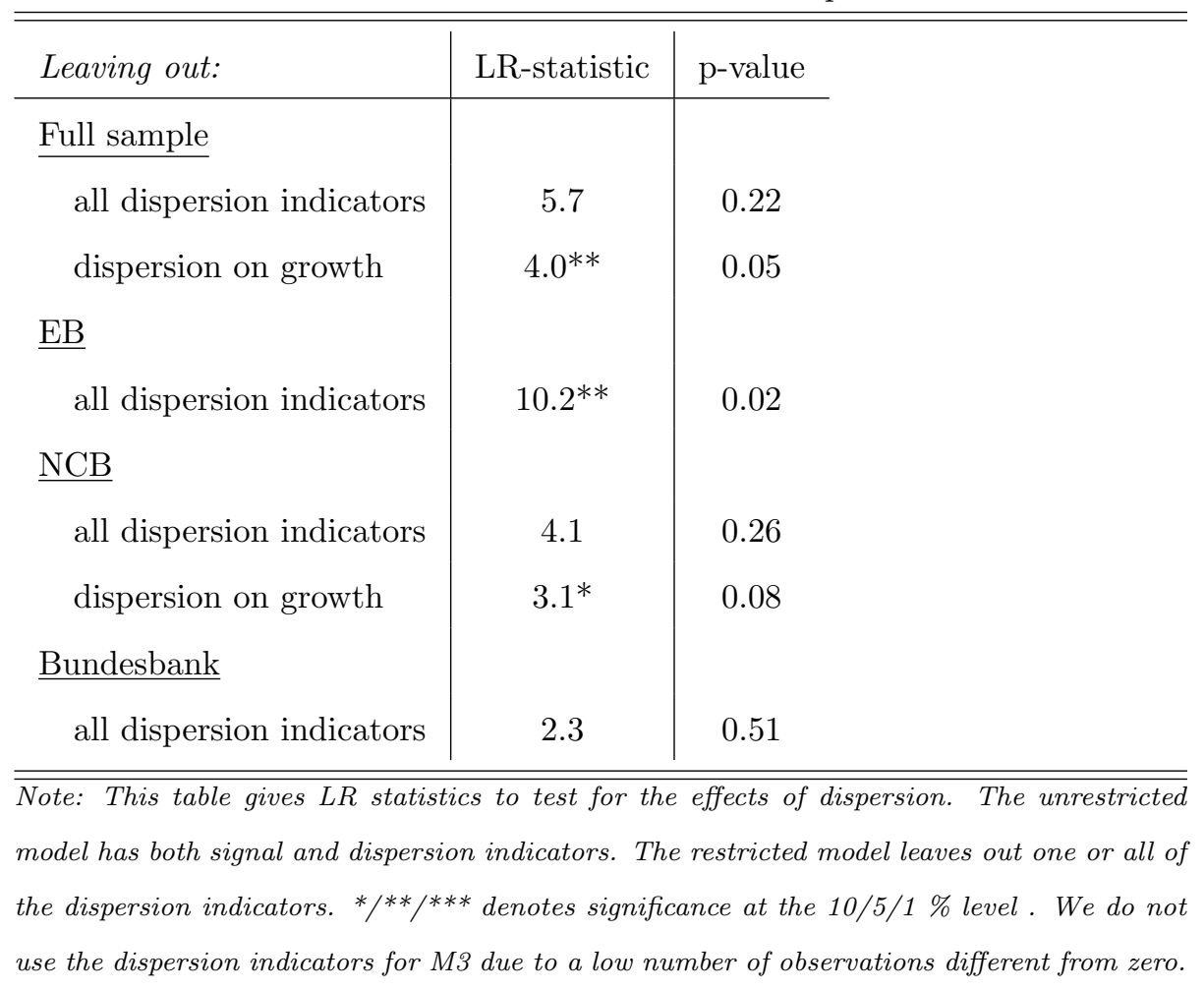




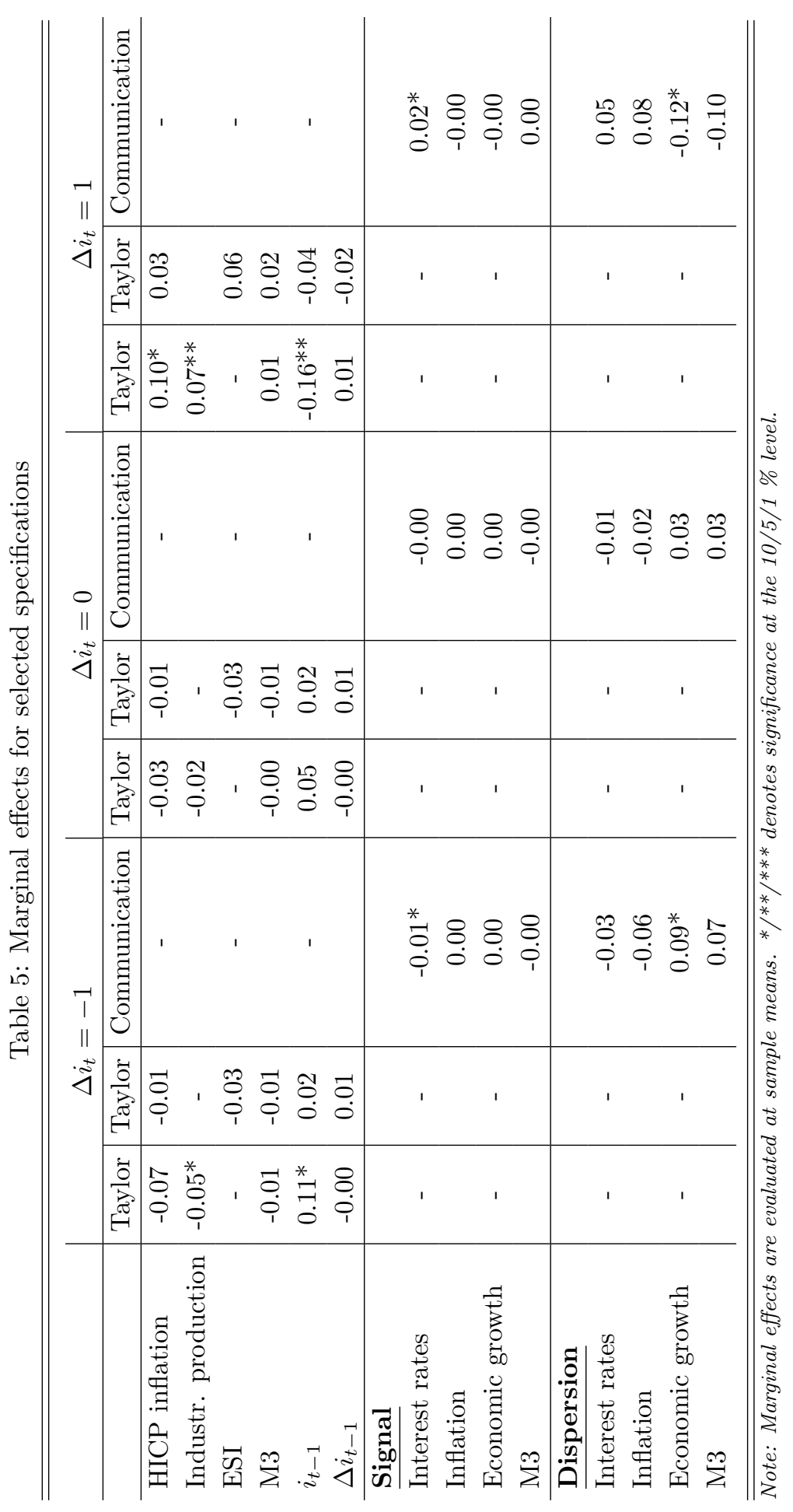


Table 6: Predictive power: full sample results

\begin{tabular}{l|c|c|c|c|c}
\hline \hline & $\begin{array}{c}\text { ECB } \\
\text { decisions* }\end{array}$ & \multicolumn{3}{|c}{ Ordered probit models } \\
\hline Tistribution & & & & & \\
\% lower rates & 6.7 & 0.0 & 4.0 & 0.0 & 0.0 \\
\% constant rates & 84.0 & 100.0 & 89.3 & 96.0 & 97.3 \\
\% higher rates & 9.3 & 0.0 & 6.7 & 4.0 & 2.7 \\
\hline \% correct & & & & & Taylor ${ }^{\ddagger}$ \\
Total & - & 84.0 & 84.0 & 82.7 & 86.7 \\
Changes & & 0.0 & 33.3 & 8.3 & 16.7 \\
Lower rates & - & 0.0 & 20.0 & 0.0 & 0.0 \\
Higher rates & & 0.0 & 42.9 & 14.3 & 28.6 \\
\hline \hline
\end{tabular}

Notes:

* This column shows the distribution of ECB interest rate changes (5 lower, 63 unchanged and 7 upward) between 4 January 1999 and 2 May 2002.

$\dagger$ This column shows results using industrial production.

¥ This column shows results using the ESI. 
Table 7: Predictive power: results for groups

\begin{tabular}{|c|c|c|c|c|c|c|c|}
\hline & \multirow{2}{*}{$\begin{array}{c}\text { ECB } \\
\text { decision* }\end{array}$} & \multicolumn{3}{|c|}{ Signal ${ }^{\dagger}$} & \multicolumn{3}{|c|}{ Signal \& dispersion ${ }^{\dagger}$} \\
\hline & & $\mathrm{EB}$ & NCB & $\mathrm{BuBa}$ & $\mathrm{EB}$ & NCB & $\mathrm{BuBa}$ \\
\hline \multicolumn{8}{|l|}{ Distribution } \\
\hline$\%$ lower rates & 6.7 & 0.0 & 0.0 & 0.0 & 0.0 & 0.0 & 5.3 \\
\hline$\%$ constant rates & 84.0 & 97.3 & 100.0 & 97.3 & 97.3 & 100.0 & 94.7 \\
\hline$\%$ higher rates & 9.3 & 2.7 & 0.0 & 2.7 & 2.7 & 0.0 & 0.0 \\
\hline \multicolumn{8}{|l|}{$\%$ correct } \\
\hline Total & - & 86.7 & 84.0 & 86.7 & 86.7 & 84.0 & 86.7 \\
\hline Changes & & 16.7 & 0.0 & 16.7 & 16.7 & 0.0 & 25.0 \\
\hline Lower rates & - & 0.0 & 0.0 & 0.0 & 0.0 & 0.0 & 0.0 \\
\hline Higher rates & & 28.6 & 0.0 & 28.6 & 28.6 & 0.0 & 42.9 \\
\hline
\end{tabular}

Notes:

* This column shows the distribution of ECB interest rate changes (5 lower, 63 unchanged and 7 upward) between 4 January 1999 and 2 May 2002.

$\dagger$ We do not use the indicators for statements on M3, as the number of observations different from zero per group is low $(\leq 7)$. 
Table 8: OLS regressions of signal indicators on Taylor variables

\begin{tabular}{l|c|c|c|c}
\hline \hline & $(1)$ & $(2)$ & $(3)$ & $(4)$ \\
& Interest rates & Inflation & Economic growth & M3 \\
\hline HICP & 2.23 & -1.92 & 0.47 & $0.69^{*}$ \\
ESI & $(1.37)$ & $(3.31)$ & $(2.10)$ & $(0.39)$ \\
& $2.35^{* *}$ & 1.70 & $3.08^{* * *}$ & $0.68^{*}$ \\
M3 & $(0.96)$ & $(1.14)$ & $(0.79)$ & $(0.34)$ \\
& -0.33 & -0.13 & $-1.44^{* *}$ & 0.02 \\
$i_{t-1}$ & $(0.46)$ & $(0.86)$ & $(0.72)$ & $(0.24)$ \\
$\Delta i_{t-1}$ & $-2.84^{* *}$ & 0.46 & $-4.29^{* * *}$ & $-1.24^{* *}$ \\
Constant & $(1.34)$ & $(2.79)$ & $(1.23)$ & $(0.57)$ \\
& 0.99 & 4.67 & 1.05 & 0.06 \\
Linear trend & $(1.22)$ & $(4.16)$ & $(1.21)$ & $(0.43)$ \\
& $7.56^{*}$ & 1.86 & $18.11^{* * *}$ & 2.92 \\
\hline Adj. $R^{2}$ & $(4.26)$ & $(8.25)$ & $(5.66)$ & $(1.76)$ \\
F-statistic & - & - & $0.14^{* *}$ & - \\
DW-statistic & $4.2^{* * *}$ & $2.4^{* *}$ & $(0.07)$ & \\
Log L & 1.9 & 2.3 & 0.10 & 0.02 \\
\hline Note: & -188.3 & -253.1 & $2.3^{* *}$ & 1.3 \\
& & & -198.9 & 2.1 \\
& 0.18 & 0.09 & -156.2 \\
\hline
\end{tabular}

Note: This table gives full sample results for OLS regressions of ECB signal indicators on the Taylor rule variables. The sample period is 4 January 1999 to 2 May 2002. Newey-West standard errors in parentheses, */**/*** denotes significance at the 10/5/1 \% level. . 
Table 9: Ordered probit regressions with predicted communication

\begin{tabular}{l|c|c|c|c}
\hline \hline & $(1)$ & $(2)$ & $(3)$ & $(4)$ \\
& Full sample & EB & NCB presidents & Bundesbank \\
\hline Signal on: & & & & \\
Interest rates & $1.02^{* * *}$ & $8.51^{*}$ & -0.40 & $2.86^{* * *}$ \\
& $(0.32)$ & $(4.87)$ & $(0.47)$ & $(0.92)$ \\
Inflation & $-0.18^{*}$ & 0.28 & $-0.25^{*}$ & $-0.86^{* *}$ \\
& $(0.09)$ & $(0.73)$ & $(0.13)$ & $(0.40)$ \\
Economic growth & -0.04 & -0.69 & $-2.70^{* *}$ & $1.61^{* *}$ \\
& $(0.23)$ & $(0.85)$ & $(1.06)$ & $(0.70)$ \\
M3 & -0.54 & $-1.96^{* *}$ & $19.70^{* * *}$ & -3.00 \\
& $(0.55)$ & $(0.91)$ & $(6.92)$ & $(2.76)$ \\
\hline$\tau_{1}$ & -1.5 & -1.1 & -3.8 & -2.1 \\
$\tau_{2}$ & 2.6 & 2.9 & 1.2 & 2.8 \\
Log pseudo-L & -29.2 & -29.4 & -28.0 & -25.8 \\
Pseudo- $R^{2}$ & 0.29 & 0.28 & 0.32 & 0.37 \\
\hline \hline
\end{tabular}

$\overline{\overline{\text { Note: }} \text { This table gives results for ordered probit regression models of ECB interest rate deci- }}$ sions if we use the predicted component of communication based on macroeconomic developments. The sample period is 4 January 1999 to 2 May 2002. Standard errors in parentheses, */**/*** denotes significance at the 10/5/1 \% level. We use Hubert-White robust estimates of variance in all cases. 
Table 10: Ordered probit regressions with filtered communication

\begin{tabular}{l|c|c|c|c}
\hline \hline & $(1)$ & $(2)$ & $(3)$ & $(4)$ \\
& Full sample & EB & NCB presidents & Bundesbank \\
\hline Signal on: & 0.09 & 0.47 & -0.12 & 0.12 \\
Interest rates & $(0.08)$ & $(0.30)$ & $(0.09)$ & $(0.09)$ \\
Inflation & -0.02 & -0.03 & 0.02 & 0.09 \\
& $(0.02)$ & $(0.04)$ & $(0.03)$ & $(0.08)$ \\
Economic growth & -0.04 & -0.03 & 0.08 & $-0.25^{* *}$ \\
& $(0.05)$ & $(0.09)$ & $(0.08)$ & $(0.12)$ \\
M3 & -0.00 & -0.05 & -0.03 & 0.08 \\
& $(0.06)$ & $(0.05)$ & $(0.17)$ & $(0.17)$ \\
\hline$\tau_{1}$ & -1.5 & -1.5 & -1.5 & -1.5 \\
$\tau_{2}$ & 1.4 & 1.4 & 1.3 & 1.4 \\
Log pseudo-L & -40.3 & -39.5 & -40.3 & -39.0 \\
Pseudo- $R^{2}$ & 0.02 & 0.04 & 0.02 & 0.05 \\
\hline
\end{tabular}

$\overline{\text { Note: This table gives results for ordered probit regression models of ECB interest rate de- }}$ cisions if we use the filtered component of communication. The sample period is 4 January 1999 to 2 May 2002. Standard errors in parentheses, */**/*** denotes significance at the 10/5/1 \% level. We use Hubert-White robust estimates of variance in all cases. 